\title{
O Uso do Smartphone por Estudantes de Pós-Graduação em Tecnologias Educacionais: Um Estudo de Caso
}

\author{
Elvis Medeiros de Melo, Dennys Leite Maia \\ Instituto Metrópole Digital - Universidade Federal do Rio Grande do Norte (UFRN) \\ Av. Sen. Salgado Filho, 3000 - Lagoa Nova, CEP: 59.078-970 - Natal - RN - Brasil \\ elvismedeiros.mm@gmail.com, dennys@imd.ufrn.br
}

\begin{abstract}
The society is experiencing moments of changing habits, due to the development of digital mobile technologies, such as smartphones. Approaches based on the use of one mobile device per student (one to one, or 1: 1) are being disseminated, among them the BYOD (Bring your own device) proposal. Given this reality, how do postgraduate students in Educational Technologies perceive the use of smartphones in educational environments? About $64 \%$ of the students with active link participated in the study. Through a case study, a survey was applied and Similitude Analysis was performed through the construction of graphs in the software IRaMuTeQ. Among the results, all students have their own smartphone with mobile internet and 51\% did not participate in training for their pedagogical use.
\end{abstract}

Resumo. A sociedade está vivenciando momentos de mudanças de hábitos, devido ao desenvolvimento das tecnologias digitais móveis, como os smartphones. Abordagens baseadas no uso de um dispositivo móvel por aluno (um para um, ou 1:1) estão sendo difundidas, entre elas a proposta BYOD (Bring your own device). Tendo em vista essa realidade, como estudantes de uma pós-graduação em Tecnologias Educacionais percebem o uso dos smartphones em ambientes educacionais? Participaram da pesquisa cerca de 64\% dos discentes com vínculo ativo. Através de um estudo de caso, foi aplicado um survey e foi realizada Análise de Similitude através da construção de grafos no software IRaMuTeQ. Dentre os resultados, todos os alunos possuem smartphone próprio com internet móvel e 51\% não participaram de formação para seu uso pedagógico.

\section{Introdução}

Vivemos em uma sociedade onde as Tecnologias Digitais da Informação e Comunicação (TDIC) estão mais presentes do que antes em nossa realidade, auxiliando na produção de textos, na criação de imagens, na realização de pesquisas (sejam elas de cunho acadêmico ou não) e no alcance de informações e/ou conhecimentos. Elas vêm colaborando com a modificação das relações humanas, contribuindo para uma mudança de paradigma comunicativo, principalmente com a expansão dos espaços digitais. Dentre as TDIC que mais estão sendo difundidas no Século XXI, estão os smartphones, e através deles, a aprendizagem móvel. Kenski (2007) ressalta que as TDIC devem promover mais a produção de novos conhecimentos e avanços na sociedade e que se faz necessária a preparação de indivíduos para lidar e interagir com o conhecimento tecnológico. 
Nesse âmbito, é importante que os professores estejam cientes das possibilidades de que podem se servir com o uso das tecnologias digitais. Como observa Kenski (2007), é preciso que os professores se sintam confortáveis para utilizar esses novos auxiliadores didáticos, como os smartphones. Estar confortável significa conhecê-los, dominar os principais procedimentos técnicos para sua utilização, avaliá-los criticamente e criar novas possibilidades pedagógicas, partindo da integração desses meios com o processo de ensino. Nesse âmbito, a BYOD (Bring Your Own Device, do Inglês: ou seja, traga seu próprio dispositivo) privilegia a utilização dos dispositivos dos próprios estudantes. Esse modelo não apresenta custos elevados para as instituições ou governos e, ainda, pode contribuir com os processos de protagonismo estudantil, que tem no smartphone um dos seus principais símbolos identitários [Balardini 2008].

No âmbito de uma Pós-Graduação em Tecnologias Educacionais, esse uso também não deve ser descartado, tendo em vista que esses profissionais estarão aptos a utilizar essas tecnologias em suas salas de aula. Com a ampla difusão dos smartphones, esse instrumento passa a ser um auxiliador para tarefas rápidas, assim como para uso pedagógico em atividades de sala de aula invertida, ou leitura de artigos, por exemplo. Para que o professor utilize o BYOD, se faz necessário um levantamento prévio, para apurar da possibilidade de utilização dos smartphones nas turmas da escola, conforme sugere Alberta Educación (2012) e outros trabalhos. Tendo em vista essa problemática, sabendo das potencialidades dessa ferramenta para o ensino, quais as perspectivas pedagógicas do uso dispositivos móveis por Estudantes de uma Pós-Graduação em Tecnologias Educacionais (EPGTE)? Discorreremos sobre essa problemática no decorrer deste estudo.

O presente artigo possui a seguinte estrutura: Além desta introdução, uma seção para fundamentação sobre o uso da BYOD em contextos educacionais, uma seção na qual discorremos sobre os procedimentos metodológicos da pesquisa, uma para a discussão dos resultados e outra para as conclusões, seguidas das referências utilizadas para a escrita do corpus do artigo.

\section{BYOD (Bring Your Own Device)}

As iniciativas de BYOD se referem a modelos de tecnologia em que os alunos levam um dispositivo de propriedade pessoal para a escola com o objetivo de aprender [Collier; Halpin 2012]. Como o engajamento estudantil é um desafio de longo prazo, é essencial projetar um novo paradigma no discurso da sala de aula sobre o uso dessas ferramentas para fins educacionais. O designer pedagógico do modelo BYOD têm como premissa princípios de aprendizagem ecológica e social construtivista, em que o papel dos alunos é alterado para ter mais engajamento na construção do conhecimento e mais acesso a conteúdos digitais para permitir personalização, participação e produtividade na sua aprendizagem [Edelson 2001].

Embora as abordagens 1:1 (um dispositivo por aluno), em geral, se baseiam na distribuição ou aquisição de dispositivos homogêneos para utilização na escola e em casa, também emerge em alguns contextos a configuração que se populariza, como a BYOD, por exemplo. Nesse sentido, três conceitos colocam-se na centralidade da compreensão desse novo paradigma de aprendizagem: ubíqua (disponível em qualquer lugar); pervasiva (transparente e integrada às atividades cotidianas); ambiente (naturalmente entrelaçada ao entorno educacional) [Vieira; Conforto 2015]. Contudo, é importante considerar que a aprendizagem móvel se apresenta integrada ao contexto da sala de aula, com potencial para manter os estudantes mais conectados e vinculados a atividades 
colaborativas. Em pesquisa recente sobre os dispositivos móveis Android, a Open Signal (2014) desenvolveu a pesquisa "Android Fragmentation 2014", na qual foram analisados 682.000 dispositivos. Concluíram que existiam 18.786 modelos diferentes, ou seja eram distintos uns dos outros (quer em termos de versão do sistema operacional, tamanho do tela, hardware). Tal diversidade pode causar alguns problemas nas situações em que os estudantes trazem para a escola o seu dispositivo pessoal na BYOD. Se a mesma pesquisa fosse realizada em 2019, seria constatado um número muito maior de possibilidades. É preciso conhecer a realidade dos alunos e recursos mais universais possíveis para uma possível prática com m-learning utilizando os smartphones dos estudantes.

Estudos da literatura sobre a BYOD já versam sobre as dificuldades encontradas para tal abordagem nas salas de aula. Sharples (2006) acrescenta que existe uma grande dificuldade em gerir equipamentos com potencialidades diferentes (diversidade decorrente da tecnologia ser propriedade dos estudantes e não uniformizada pela escola). Basta analisar a diversidade de dispositivos Android no estudo da OpenSignal (2014) para perceber que a logística que envolverá uma aula com tantos dispositivos diferentes, pode ser devastadora. Um app, por exemplo, pode funcionar no smartphone de dez estudantes e não funcionar no smartphone de dois estudantes por terem uma versão mais antiga ou desatualizada. O levantamento prévio dos modelos de smartphones dos estudantes é essencial. Segundo mostra o Quadro 1, podemos observar os modelos de BYOD proposto por Alberta Educacíon (2014) em seu estudo sobre as possibilidades de integração dessa política pública nas escolas canadenses.

\begin{tabular}{|c|c|c|c|}
\hline Standartização & & & Flexibilidade \\
\hline Modelo 1 & Modelo 2 & Modelo 3 & Modelo 4 \\
\hline $\begin{array}{c}\text { Limitar os } \\
\text { dispositivos a uma } \\
\text { marca e modelo }\end{array}$ & $\begin{array}{l}\text { Limitar os } \\
\text { dispositivos a } \\
\text { especificações } \\
\text { técnicas: SO, } \\
\text { capacidade de } \\
\text { ammazenamento, } \\
\text { acesso à internet }\end{array}$ & $\begin{array}{c}\text { Limitar os } \\
\text { dispositivos a } \\
\text { capacidades } \\
\text { especificas: } \\
\text { software, apps, entre } \\
\text { outras. }\end{array}$ & $\begin{array}{l}\text { Năo limitar o tipo de } \\
\text { dispositivos, } \\
\text { exigindo apenas que } \\
\text { permitam o acesso à } \\
\text { internet }\end{array}$ \\
\hline
\end{tabular}

Assim, o modelo 1 da BYOD é potencialmente mais vantajoso para professores, pois na sala de aula apenas existe um modelo de dispositivo, o que facilita a preparação de aulas e a sua execução, enquanto o modelo 4, no caso mais extremo, podem existir tantos dispositivos diferentes como estudantes. Isso pode dificultar a aplicabilidade de certas apps, ou visualização de vídeos, exigindo do professor um conhecimento acurado sobre vários dispositivos diferentes, promovendo uma maior flexibilidade para a aplicação do método BYOD. O modelo 4 também pode causar muitas desvantagens, como a disponibilidade de menos apps que podem ser usados de maneira universal, assim como alguma desigualdade no acesso dos alunos, já que nem todos os dispositivos são criados iguais quando se trata de usabilidade e de modelos. Uma possibilidade é o professor planejar suas aulas utilizando recursos primários de um smartphone, como a câmera, editor de texto ou navegador de internet (Browser).

Em estudo sobre a BYOD, Estable (2013) fala sobre as vantagens e desvantagens do método, e faz algumas questões a serem consideradas durante a implementação da BYOD em uma sala de aula. Segundo o autor, muitas instituições estão começando a 
implementar uma política do modelo BYOD, na qual alunos e professores recebem especificações mínimas para os dispositivos que devem escolher, tais como dispositivos Android, além de algumas apps específicas. Se a BYOD será bem sucedida em uma sala de aula dependerá de muitos fatores. De acordo com Estable (2013), precisamos considerar as questões técnicas e não técnicas, como tipos de arquivo, de apps, organização do conteúdo de aprendizagem, tamanho da tela para a informação a ser exibida, aceitação cultural e linguística, conectividade da rede sem fio WiFi e a motivação dos estudantes para usar os dispositivos móveis para aprender.

\section{Procedimentos Metodológicos da Pesquisa}

Esta pesquisa caracteriza-se como um Estudo de Caso Exploratória, pois a questão de pesquisa tem o intuito de estudar e responder uma pergunta para uma realidade específica [Yin 2005]. No caso, trata-se dos EPGTE. Para coleta de dados, foi elaborado um survey com perguntas de carácter qualitativo, por exemplo, a faixa etária, o ano de ingresso na pós-graduação, entre outras. Além disso, para análise, Yin (2005) recomenda que, a partir dos dados provenientes de surveys (questionários), sejam criados e analisados dados estatísticos. Um survey foi elaborado utilizando a ferramenta do google formulários e compartilhados nos grupos de WhatsApp de cada turma da pós-graduação em questão. A amostra foi significativa, considerando o número de discentes ativos. Participaram cerca de $2 / 3(65,15 \%)$ dos EPGTE.

Para traçar o perfil dos EPGTE, perguntamos qual a faixa etária, quantos celulares o EPGTE já possuiu, qual a marca do celular, o que tanto esse aluno usa no smartphone, qual recurso do smartphone ele mais usa, quanto tempo é gasto no manuseio do aparelho por dia, se já participou de alguma formação para uso pedagógico do smartphone, e se já usou o celular para estudar. Todas essas perguntas serviram para o delineamento de categorias de análise, que foram identificadas com uma ID, respectivamente: $i d$, qtdd, marca, mais, tempo, form, estudar.

Perguntas adicionais foram elaboradas no survey, tais como: se o EPGTE possuía internet móvel em seu celular, qual o ano de ingresso, se ele possui um celular para uso pessoal, quais aplicativos ele usa, qual o local mais frequente de acesso a internet pelo smartphone, e algumas perguntas relacionadas aos seus aparelhos específicos, como se possuía leitor de QR-Code, por exemplo.

Para análise de conteúdo das produções escritas dos pós-graduandos, utilizamos o software IRaMuTeQ1. O software, a princípio, possui sua versão mais básica na língua francesa, e é bastante utilizado na análise de conteúdos, análise de similitude, método Reineit de classe de palavras e criação de nuvem de palavras. Neste trabalho, utilizaremos a técnica de Análise de Similitude de Jaccard2, na qual faz relação entre as palavras do discurso através da teoria dos grafos. Assim, foi possível identificar as ocorrências entre as palavras e as indicações da conexidade entre as palavras, auxiliando na identificação da estrutura do conteúdo de um corpus textual.

Com o software, também foi possível fazer cruzamento entre variáveis qualitativas do perfil do aluno. Para isso, precisamos formatar o texto de acordo com o padrão aceitável para a aplicação (ver Figura 1).

1 Disponível em: <http://www.iramuteq.org/>. Acesso em: 26 jun. 2019.

$2 \mathrm{O}$ leitor poderá encontrar mais detalhes em $<$ https://bit.ly/2Jh5vqR>. Acesso em: 29 jun. 2019. 


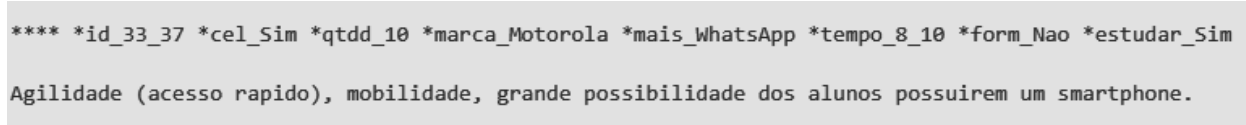

Figura 1. Texto formatado para uso no IRaMuTeQ

De acordo com as perguntas para traçamento do perfil do EPGTE, afim de responder a pergunta principal deste estudo, pedimos para os EPGTE responderem como ele usa esse aparelho para estudos pessoais e quais os pontos positivos e negativos eles identificam para o uso dos smartphones em uma sala de aula. Para discussão dos resultados, alinhamos os grafos obtidos com a teoria acerca do uso dos smartphones na sala de aula de acordo com o relato dos EPGTE.

\section{Resultados e Discussões}

Analisando o perfil da turma de EPGTE, observando a variável idade (ver Gráfico 1), que a grande está na faixa etária de 28 a 37 anos. Ao repararmos a variável quantidade de smartphones obtidos (ver Gráfico 2), verificamos que uma grande maioria (91\%) dos EPGTE possuíram mais que 4 smartphones em toda a sua vida. Segundo Google Consumer Barometer3, os smartphones tiveram um aumento na sua popularidade e vendas no Brasil a partir de 2010. Isso nos mostra que os EPGTE estão trocando de celular aproximadamente a cada 2 anos. Um fato a ser observado também é que os EPGTE mais jovens trocaram de aparelho mais vezes que os estudantes com idades maiores que 43 anos.

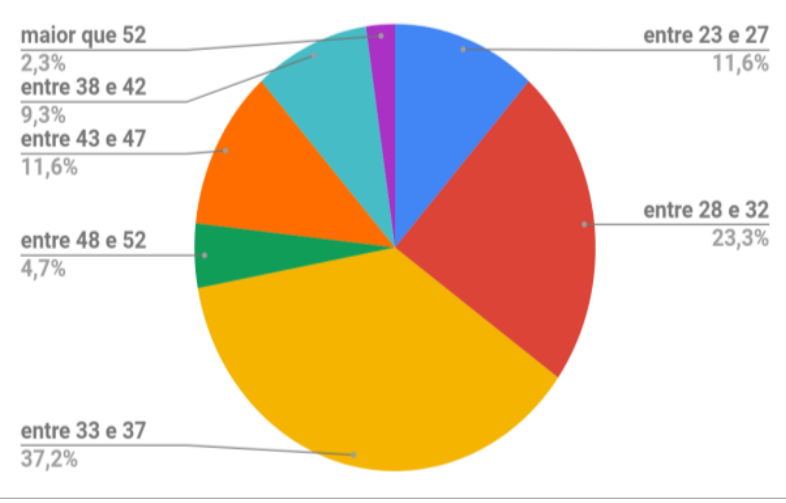

Gráfico 1. Faixa etária dos EPGTE

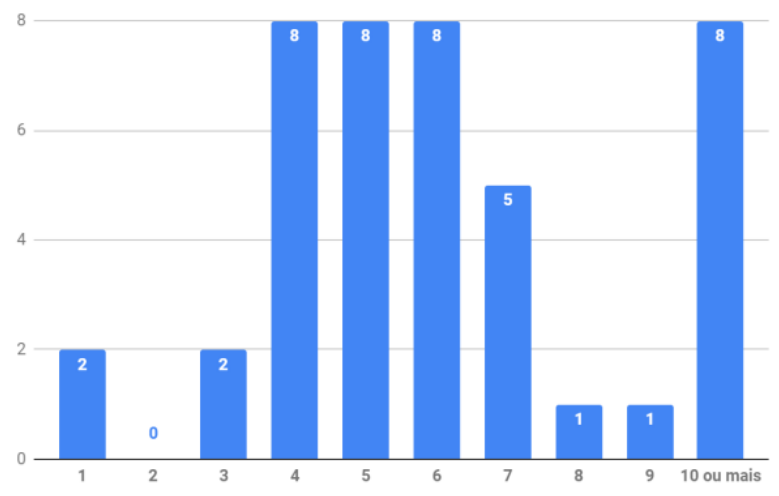

Gráfico 2. Quantidade de smartphones já possuídos por EPGTE

Ao analisarmos a marca dos aparelhos dos EPGTE, observamos o smartphone atual de $42 \%$ dos estudantes são da marca Motorola, 35\% da Samsung, 7\% da marca Xiaomi, 11\% iPhone e 5\% LG, ou seja, 89\% dos smartphones desses estudantes possuem sistema operacional Android. Esse dado pode facilitar o planejamento de aulas utilizando m-learning por professores da pós-graduação em questão. Pelo modelo proposto pela Alberta Educación (2012), esses professores podem pensar em atividades utilizando alguns recursos pré-instalados no Android. Ao analisar a presença de internet móvel no smartphone destes estudantes, todos responderam possuir. A preocupação do professor ficaria em torno do recurso escolhido para integração dessa tecnologia em sala de aula. 
Perguntando aos EPGTE o que mais utilizam no smartphone, 79\% responderam que usam mais o WhatsApp, 11,6\% utilizam para realizar pesquisas na internet, 2,3\% usam mais o Instagram e 7\% utilizam mais jogos. Assim, é recomendado que os professores usem o recurso do WhatsApp em suas práticas, pois, ao perguntar quais os recursos do smartphone eles usam, todos responderam que faziam uso do WhatsApp. Além disso, 79\% estão com esse aplicativo aberto por mais tempo que os demais. Uma prática comum e bastante utilizada é a criação de grupos de conversa e compartilhamento de materiais de estudo e discussões de questões [Maia 2016].

Um fato interessante a ser notado é que, apesar de os EPGTE estarem inseridos em um programa de pós-graduação específico para o uso de tecnologias na educação, apenas $48,8 \%$ já participaram de alguma formação para uso pedagógico dos smartphones. Ao analisar os que não participaram $(51,2 \%)$, observamos que o ano de ingresso não influencia esse resultado, ou seja, há alunos da turma 2019, da turma 2018 e da turma 2017 (que já estão concluindo) que não participaram de cursos para o uso dessa ferramenta em contextos educacionais. Esse fato é preocupante e sugere a criação de tópicos em disciplinas obrigatórias ou formação continuada com esse tema. Maia e Barreto (2012) afirmam que os novos docentes que estão chegando às escolas, embora habituados ao trabalho com os computadores, por não terem recebido formação pedagógica para o trabalho com as tecnologias digitais, também não estão aptos para usálos como ferramenta didática. Dessa maneira, cabe às Instituições de Ensino Superior, através de seus cursos de formação de professores, rever seus currículos.

Para a variável horas de acesso por dia, observamos que os estudantes mais jovens passam mais tempo no celular (em média 7 horas diárias), em contrapartida aos estudantes com mais de 43 anos, que passam, no máximo, 4 horas por dia. Destes estudantes, apenas 2 responderam que nunca utilizam o smartphone para estudar. Esses dois possuem faixa etária maior que 43 anos e nunca participaram de um curso para uso pedagógico do smartphone. Ao cruzar as variáveis com o discurso sobre como os EPGTE estudam utilizando o smartphone, utilizando a análise de similitude para gerar grafos através do IRaMuTeQ, tivemos um aproveitamento de $68,03 \%$ das palavras, sendo que $23,31 \%$ apareceram apenas uma vez ou são conectivos, artigos definidos/indefinidos, pronomes, entre outros. Ao gerar o grafo relacionado a esse banco de dados específico, gerando um relatório com árvore máxima selecionada (ver Figura 2(a)) e não (ver Figura 2(b)), observamos que as palavras que mais se repetiram formaram as comunidades "Pesquisa", "Vídeo", "Leitura", "Texto", "Aula", "Online", "Internet", "Assistir" e que palavras como "Vídeo" tem relação com "Aula", "Assistir" e "Leitura", assim como "pdf" tem forte relação com as comunidades "Online" e "Internet". Isso significa que os EPGTE utilizam mais o smartphones para atividades relacionadas à estudo, como leitura de textos, pesquisas na internet, vídeo-aulas no YouTube, por ser mais fácil o acesso, por ser extensão do computador, por proporcionar mobilidade.

Ao perguntar sobre os pontos positivos do uso do smartphone, sob uma perspectiva educacional para os EPGTE, observamos que, da mesma forma como foi realizado para a primeira pergunta, obtivemos um aproveitamento de $65,57 \%$ do conteúdo. Ao gerar o grafo relacionado a esse banco de dados, gerando um relatório com árvore máxima selecionada (ver Figura 3(a)) e não (ver Figura 3(b)), observamos que as palavras que mais se repetiram foram "Aluno", "Acesso", "Aula", "Interação", "Uso", compondo comunidades de palavras próximas a uma ramificação do grafo. Da mesma forma, ao analisar o grafo da Figura 3(b) (sem árvore máxima), observamos que as comunidades "Aluno", "Acesso" e "Uso" se sobrescrevem. 

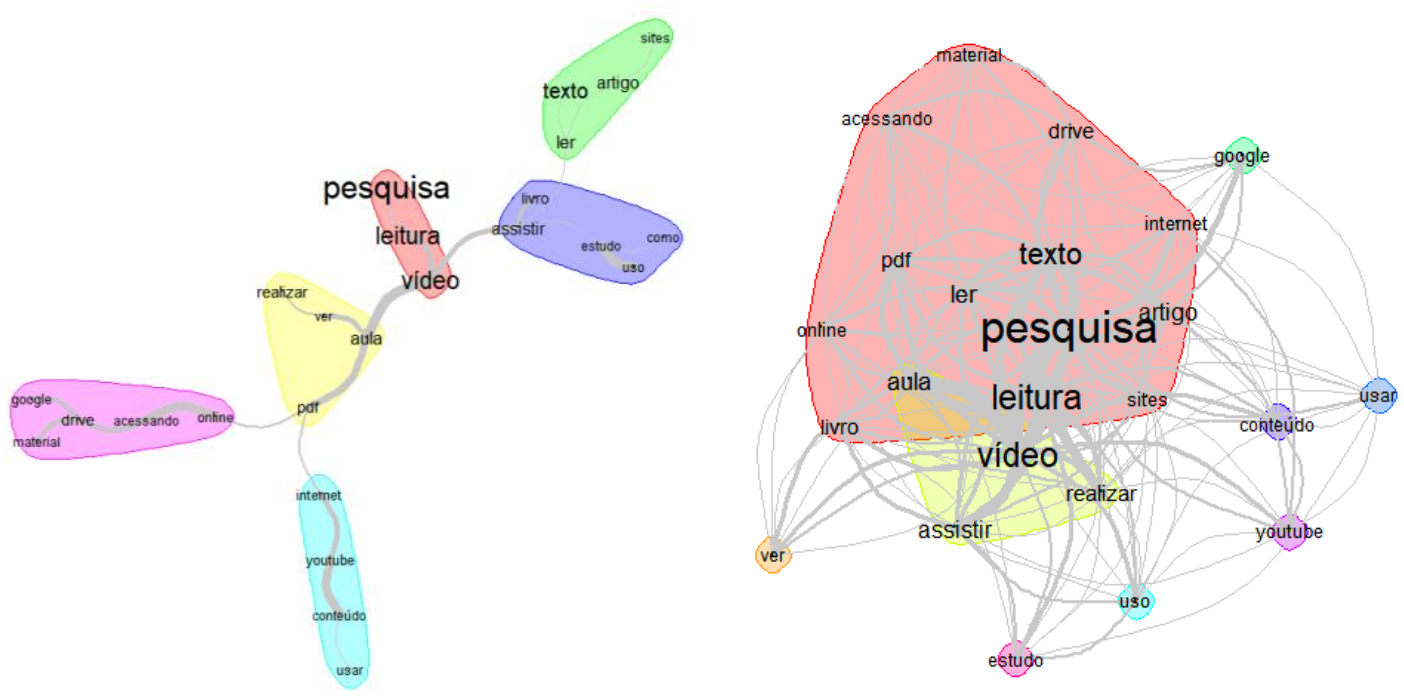

Figura 2. Grafo sobre o uso do smartphone por alunos da EPGTE (a) com árvore máxima - à esquerda (b) sem árvore máxima - à direita.
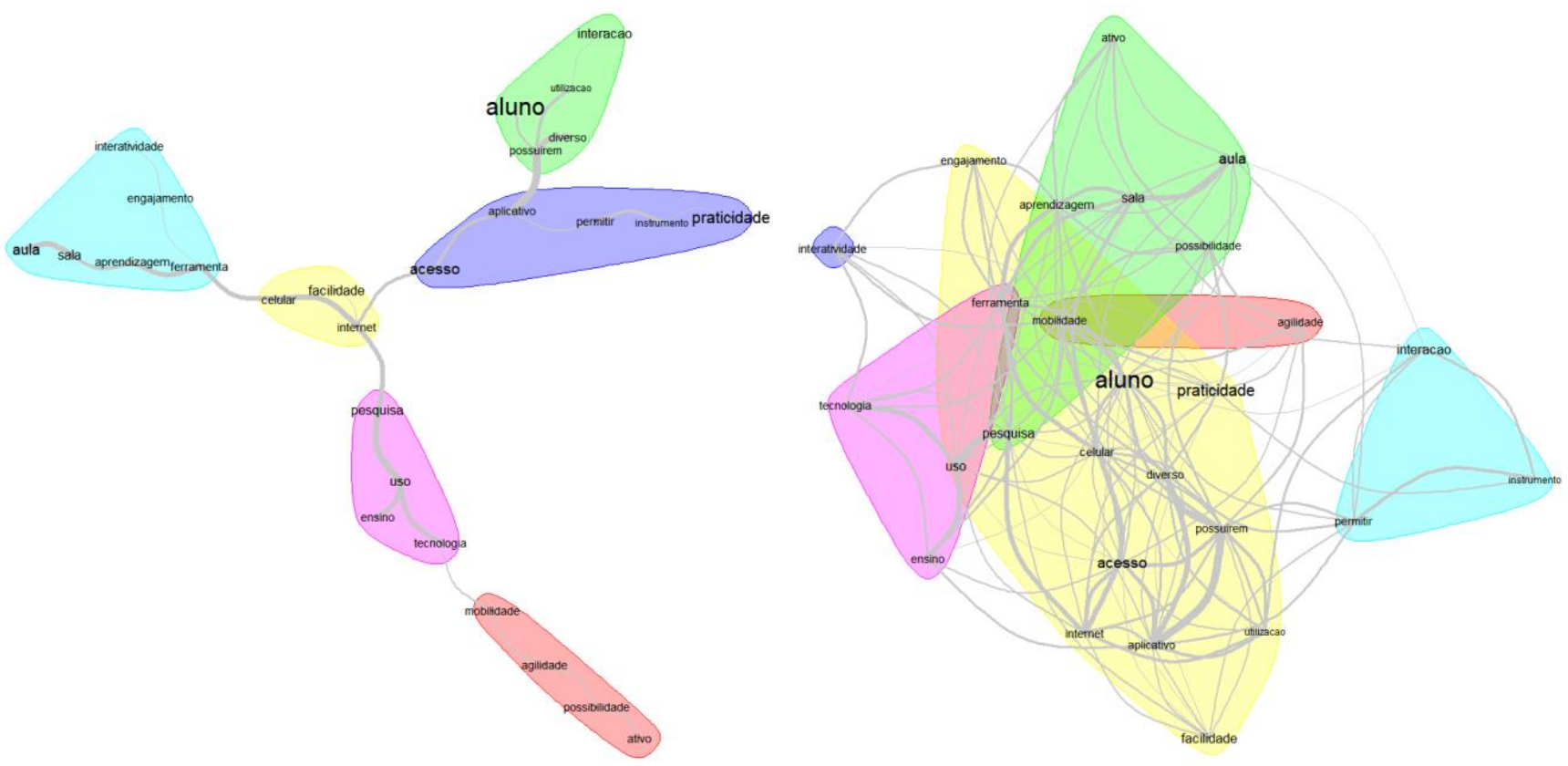

Figura 3. Grafo sobre os pontos positivos do uso dos smartphone por alunos da EPGTE (a) com árvore máxima - à esquerda (b) sem árvore máxima - à direita.

Por meio dos grafos gerados pelo IRaMuTeQ, podemos concluir que os EPGTE acreditam que o uso dos smartphones pelo aluno, de maneira geral, está ligada diretamente a uma possível ferramenta para uso na sala de aula, que promove aprendizagem e mobilidade. Além disso, permite a interação e facilita o acesso a internet por meio de aplicativos, por exemplo, promovendo engajamento, interatividade e melhorar a qualidade do ensino. Considerando o uso dos smartphones, pode-se observar a presença do celular entre parte significativa dos alunos e durante as aulas, entretanto o uso desses dispositivos está, na maioria das vezes, desconectada dos processos de ensino e aprendizagem, ou até mesmo mostrando prejudicial a estes processos [Nagumo 2014]. Por mais que os EPGTE tenham um pensamento alinhado ao uso desse recurso na sala de 
aula, é interessante que haja formação para o seu uso pedagógico, integrando à conteúdos e metodologias que aproximem o aluno da aprendizagem.

Ao perguntar sobre os pontos negativos do uso do smartphone, sob uma perspectiva educacional para os EPGTE, tivemos um aproveitamento de 66,50\% do conteúdo. Ao gerar o grafo relacionado a esse banco de dados, gerando um relatório com árvore máxima selecionada (ver Figura 4(a)) e não (ver Figura 4(b)), observamos que as palavras que mais se repetiram foram "Dispersão", "Aluno", "Aula" e "Uso". Com a árvore máxima não selecionada, observamos que a comunidade "Aluno" se sobrescreve a comunidade "Dispersão", assim como a comunidade "Uso". É criada uma nova comunidade chamada de "Acesso a Internet", sugerindo que o problema não necessariamente é a disponibilidade da internet WiFi, por exemplo, nas escolas.
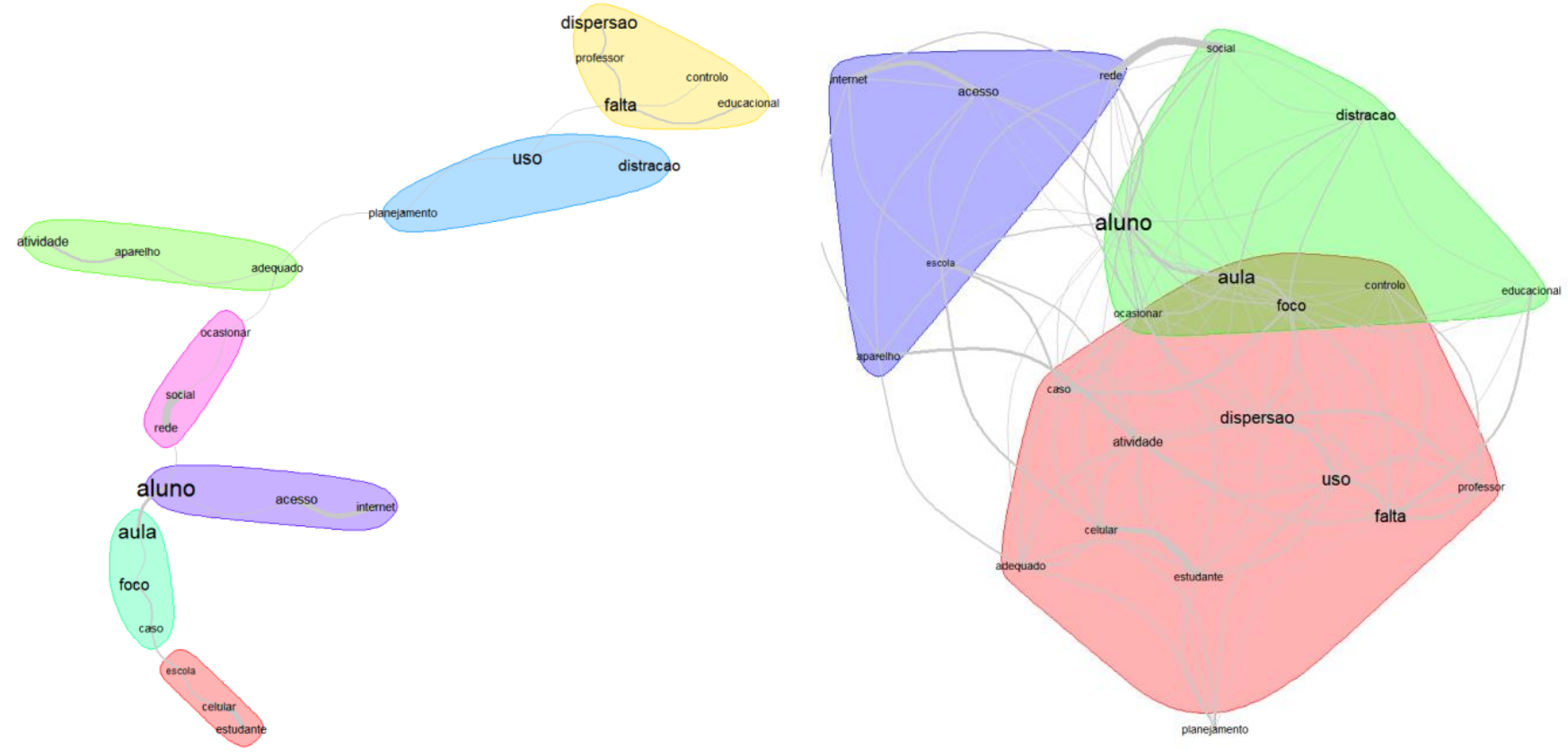

Figura 4. Grafo sobre os pontos negativos do uso dos smartphone por alunos da EPGTE (a) com árvore máxima - à esquerda (b) sem árvore máxima - à direita.

Dos grafos gerados pelo IRaMuTeQ, podemos inferir que os EPGTE acreditam fortemente que uma aula sem planejamento adequado, supervisão e orientação do professor pode causar dispersão, além disso acreditam que o smartphone pode tirar o foco dos estudantes no momento da atividade por estar conectado as redes sociais por meio da internet. A seguir, apresentamos as conclusões que o trabalho nos sugeriu realizar.

\section{Conclusões}

De acordo com os resultados, acreditamos que uma Análise de Similitude de Jaccard foi adequada para o tratamento dos dados coletados dos EPGTE. O estudo de Caso Exploratório pode concluir diversas informações sobre o uso da estratégia BYOD no âmbito desta pós-graduação. Além disso, os EPGTE levantaram alguns problemas, como o alto índice de dispersão que pode ser ocasionado por uma aula integrando o smartphone sem um planejamento adequado. Questões técnicas foram apuradas com o intuito de dar uma visão geral de como essa ferramenta poderá ser usada em aulas da pós, como o sistema operacional de seus aparelhos, metadado relacionado à marca de seus aparelhos. 
Apesar de não ter sido censitária, a pesquisa obteve uma amostra significativa $(65,15 \%)$ dos EPGTE.

Assim, conclui-se que, de forma geral, os participantes da pesquisa entendem que para utilizar as TDIC de forma pedagógica é necessário que o professor além de uma formação adequada, estejam atentos ao um mundo em rede exige que conhecimento razoáveis em informática e das potencialidades das tecnologias existentes, entre elas, o smartphone. Estas são fundamentais para que se consiga desenvolver seu conhecimento digital trabalhando de forma didática e utilizando diversos meios para se trabalhar a tecnologia como recurso pedagógico. Em um próximo estudo, para fins de especificação do modelo BYOD, que a coleta de dados aconteça de modo presencial, com o intuito de o pesquisador ajudar os entrevistados a descobrirem qual o seu modelo de smartphone, com funcionalidades mais específicas, tais como: sistema operacional, suas versões ou se o dispositivo já vem com aplicativos pré-instalados, entre outras.

\section{Referências}

Alberta Education (2012). Bring your own device: a guide for schools. In: $<$ http://education.alberta.ca/admin/technology/research.aspx >. Acesso: 30 jun. 2019.

Balardini, S. (2008). De deejays, floggers y ciberchabones: subjetividades juveniles y tecnocultura. In: Bendit, R.; Hahn, M.; Miranda, A. (Ed.). Los jóvenes y el 90 futuro: procesos de inclusión social y patrones de vulnerabilidad en un mundo globalizado. 1. ed. Buenos Aires: Prometeo Libros.

Collier, L. and Halpin, J. (2012). One-to-One 2.0: Building on the "Bring Your Own Device" (BYOD) Revolution, e.Republic.

Edelson, D. C. (2001). 'Learning-for-use: a framework for the design of technologysupported inquiry activities', J. Res. in Science Teaching, Vol. 38, No. 3, pp.355-385.

Kenski, V. M. (2007). Tecnologias também servem para fazer educação In: Educação e Tecnologias O Novo Ritmo da Informação. 3.ed. Campinas, SP: Papirus, p.43-62.

Maia, D. L.; Barreto, M. C. (2012). Tecnologias digitais na educação: uma análise das políticas públicas brasileiras. Educação, Formação \& Tecnologias, 5 (1), 47-61.

Maia, D. L. (2016). Aprendizagem Docente sobre Estruturas Multiplicativas a Partir de uma Formação Colaborativa Apoiada em Tecnologias Digitais. Tese de Doutorado, PPGED-UFC, Fortaleza.

Nagumo, E. (2014). O Uso Do Aparelho Celular Dos Estudantes Na Escola. 100f. Dissertação (Mestrado em Educação) - Faculdade de Educação, Universidade de Brasília, Brasília.

OpenSignal. (2014). Android Fragmentation $2014 . \quad$ In: $<$ http://opensignal.com/reports/2014/android-fragmentation/>. Acesso: 01 jul. 2019.

Shahar, D.; Sayers, M. G. L. (2018). Prominent exostosis projecting from the occipital squama more substantial and prevalent in young adult than older age groups. In: https://doi.org/10.1038/s41598-018-21625-1. Acesso em: 30 jun. 2019.

Sharples, M. (2006). Big Issues in Mobile Learning: Report of a workshop by the Kaleidoscope Network of Excellence Mobile Learning Initiative: U. of Nottingham.

Sousa, A. F.; Miranda, A. C. O. (2018). Os problemas causados pelo uso excessivo de smartphones. In: https://bit.ly/2NqtuJe. Acesso em: 29 jun. 2019. 
Vieira, M. C.; Conforto, D. (2015). Aprendizagem Móvel e Multimídia: a produção de material pedagógico na perspectiva BYOD. In: CBIE-LACLO 2015. Anais do XXI Workshop de Informática na Escola (WIE 2015).

Yin. R. K. (2005). Estudo de caso: planejamento e métodos. 3 ed., Porto Alegre: Bookman. 